\title{
Removing the opportunity for contract cheating in business capstones: a crime prevention case study
}

\author{
Michael Baird ${ }^{1 *}$ and Joseph Clare ${ }^{2}$
}

\author{
* Correspondence: \\ Michael.Baird@cbs.curtin.edu.au \\ ${ }^{1}$ Curtin Business School, Curtin \\ University, Rm 408.2008, Kent Street, \\ Bentley, WA 6102, Australia \\ Full list of author information is \\ available at the end of the article
}

\begin{abstract}
Introduction: With a definition that is evolving, a serious component of the contract cheating issue involves individuals paying a third-party to complete assessment items for them and then submitting this work as if it were their own. The issue of contract cheating poses a significant problem for tertiary institutions. The research literature conducted to date has addressed contract cheating, yet few papers discuss theory-based prevention strategies, and even fewer still evaluate the impact of theory-based prevention strategies.
\end{abstract}

Case description: This paper discusses a case study of contract cheating that was identified in a business simulation operating in a capstone unit at a large Australian university. The problem is outlined, the theory-based intervention is explained, and the impact on the contract cheating problem is quantified.

Discussion and evaluation: Building on a platform provided by criminological theory and crime prevention practice, the Unit Coordinator systematically adjusted a large number of assessment elements to ensure contract cheating was less likely. Importantly, this intervention was effective but also did not disadvantage students who were not engaging in contract cheating.

Conclusions: Overall, this paper connects criminological theory and crime/problem prevention practice with academic misconduct issues with the intent of demonstrating there is potential to minimise the opportunity for contract cheating by altering the opportunity structures for assessment items. Crucially, this can be done without impeding genuine student efforts and does not depend on apprehension and conviction.

Keywords: Contract cheating, Situational crime prevention, Academic misconduct, Business simulation, Capstone course

\section{Background}

When a student pays a third-party to complete assessment items that they subsequently submit as if it was their own work, they have engaged in a form of academic misconduct that forms a serious part of the 'contract cheating' problem (Clarke \& Lancaster, 2006; Lancaster \& Clarke, 2017; Walker \& Townley, 2012). Recent work by Curtis and Vardanega (2016) indicated that prevalence rates of students who admitted engaging at least once in contract cheating ranged from $3.5 \%$ in 2006 to $2.8 \%$ in 2015 . Other prevalence studies have estimated a wide variation in frequency at which students have engaged at least once in 
contract cheating, ranging from 1\% (Maxwell, Curtis, \& Vardanega, 2006) to 7.9\% (Zafarghandi, Khoshroo, \& Barkat, 2012). Despite these relatively small prevalence estimates, the issue of contract cheating poses a significant problem for tertiary institutions. There is evidence that repeat offending is common, with Curtis and Clare (2017) finding that almost $63 \%$ of students who reported engaging in contract cheating admitted that they had done so on multiple occasions. Furthermore, this form of academic misconduct has the potential to devalue tertiary qualifications, disadvantage honest, diligent students, and risks enabling unskilled, unqualified contract cheaters using unethically-gained qualifications to secure employment that they are not capable of undertaking. Indeed, Wallace and Newton (2014, p. 236) recently indicated that, "the single greatest need is for more high-profile research in [the contract cheating] area, to educate educators about the existence and detail of the problem". With this significance in mind, the following section discusses theory and strategies that have been demonstrated to successfully prevent crime and community safety problems and explores the relevance of these approaches to the design and implementation of academic assessment and evaluation to minimise contract cheating.

\section{Opportunity, crime, and situational prevention}

It is clear from criminological research that even highly motivated offenders do not offend constantly, with the decision to offend mediated by context and opportunity (Eck, 2015). The rational choice perspective (Cornish \& Clarke, 1986; Cornish \& Clarke, 2017) explains that patterns occur because offenders make crime-specific 'rational' choices, 'bounded' by factors such as time, cognitive ability, and available information, and are influenced by the perceived costs and benefits of their actions. According to the rational choice perspective, the 'perceptions' of the immediate situation and the corresponding risks/rewards of offending are much more important in influencing the decision to offend relative to the longer-term consequences of being apprehended for offending (Cornish \& Clarke, 2017). Crime events can be thought of in terms of 'scripts', and factors that occur before, during, and after a crime play an important role on the perceived rationality of the offending action (see Leclerc, 2017, for an overview of the literature around crime scripts and rational choice). Decisions to offend vary at different stages of an offence 'script' and there are individual differences in the perceived suitability of opportunities (Cornish \& Clarke, 2017; Leclerc, 2017). One crucial assumption of the rational choice perspective is that crime decisions can be made by anyone (not just people who have offended in the past), provided they perceive the immediate contextual rewards to outweigh the risks and effort involved with the offending decision. There is existing contract cheating research that demonstrates the relevance of this theory. Rigby, Burton, Balcombe, Bateman, and Mulatu (2015) found that over 50\% of students presented with a hypothetical decision-making task about university assessment items were willing to cheat if the risk of detection was low. This likelihood of cheating increased for students for whom English was a second language. Ogilvie and Stewart (2010) also demonstrated the importance of rational choice and opportunity in academic misconduct through use of a scenario-based survey that found the situational perceptions of risk and reward significantly predicted the intention to plagiarise.

From a crime prevention perspective, the set of assumptions made by the rational choice perspective explain that crime in many circumstances is not inevitable: because offenders are choosing to offend where and when they do because of the immediate 
perceptions of risk, reward, and effort involved, it is possible to alter the interaction between those factors to make offending less rational (Cornish \& Clarke, 1986; Cornish \& Clarke, 2017). For these reasons, the rational choice perspective underpins the 25 techniques of situational crime prevention (see, Clarke, 2017, for a comprehensive discussion of this framework, which has been adapted and developed since the 1980s), which have been demonstrated to effectively reduce crime problems around the world for the last 35 years by manipulating the risk, reward, effort, excuses, and provocations involved with the decision to offend (see Table 1 for the details of these techniques). ${ }^{1}$ Looking broadly at academic misconduct, recent work by Hodgkinson, Curtis, MacAlister, and Farrell (2015) has developed a portfolio of tactics for discouraging this behaviour that they located within the 25 techniques of situational crime prevention. It is fundamental to the success of the situational crime prevention approach that it does not rely on detection, apprehension, and prosecution as the sole means of controlling problems. ${ }^{2}$ This nonreliance on detection is particularly important when considering contract cheating, as this type of misconduct results in the submission of work that is promised to be 'original', meaning that typical methods of plagiarism detection (such as text matching software) are unlikely to be consistently effective identification tools for this problem. The remainder of this paper uses a case study to demonstrate the capacity that these situational prevention strategies have in order to alter an opportunity structure that was conducive for contract cheating. Importantly, as is explained, this opportunity-reducing intervention is designed to make contract cheating less likely without disadvantaging students who are not engaging in this type of academic misconduct.

\section{Contract cheating in a business capstone: Case study}

The business capstone unit structure pre-2016

This case study is taken from a major Western Australian university where a Business Capstone Unit (the Unit) is a final study period (semester/trimester) unit every Bachelor of Commerce student must complete in order to graduate. The Unit typically has approximately 2500 students enrolled per year across campuses in Australia and overseas. The Unit requires students from Accounting, Business Law, Economics, Information Systems, Management, and Marketing majors to work in multidisciplinary teams. This enables students to learn from each other and is designed to give students an overall understanding of the different areas of business outside their chosen major and to see how these diverse areas intersect and interact in practice.

Up to the end of 2014 the assessments in the Unit were varied and well-rounded, consisting of a business simulation (40\% of the Unit mark), an individual case study (20\%), a series of weekly eTests (20\%), and a presentation (20\%). The business simulation assessment had three separate components: (a) a preparation task component (10/40 marks) involving a series of quizzes and exercises designed to give students a sound knowledge and understanding of the running of the simulation with marks awarded for completion (as opposed to accuracy); (b) a peer evaluation (5/40 marks) involving online peer evaluation at two points throughout the running of the simulation, with marks tabulated at the completion of the second peer evaluation; and (c) the final result for the business simulation (25/40 marks). The simulation was run as a competitive environment, whereby six teams (including one computer competitor) competed for top ranking in 


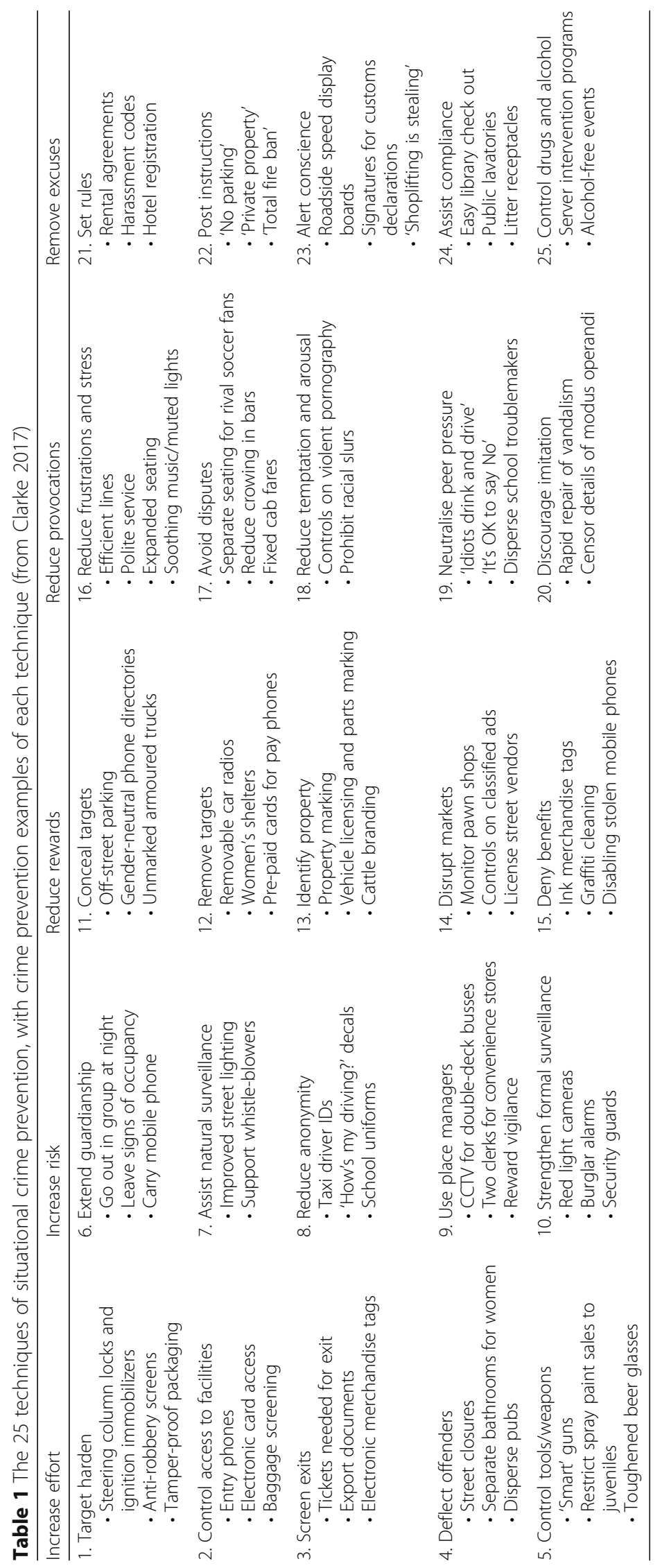


success measures set out by the team itself, which could include profit, market share, asset turnover, etc. Students could score 25/25 for this assessment if their team was well run over the eight round (year) period.

The individual case study was based upon a video interview from a real company, recorded specifically for the course. In 2015 the course had a bank of video cases that had been used for the past few years. The students were provided with information about the problem of the case and the cause of the problem, and were then left to research some alternatives and develop a solution for the case, which was framed as if it were being given to the interviewee.

The eTests were a series of weekly electronic tests to be done in the students' own time outside of class as preparation for attending the class. The assessment was spread over 10 classes, whereby each eTest was worth $2 \%$ (i.e., $10 \times 2$ marks $=20$ marks). The eTests contained multiple choice questions written on the journal article readings, video interview viewings, and simulation components for each week. Every eTest question was written purposefully for the Unit. A bank of approximately 50 questions were written for each week's eTest with students randomly assigned a set of 10 questions to answer. The order of both the selected questions and their answers were randomly varied.

The presentation was conducted in the final contact week of the study period. Students presented their running of the company in the simulation to the class, pitched as if they were the board of the company. Regardless of whether the company performed well or poorly, students were still able to present their decisions in a way that demonstrated their knowledge. Students were marked on both their individual presentation (10/20 marks) and the team's presentation (10/20 marks).

\section{Uncovering a problem}

At the end of 2014 there was a change within the Unit and a new Unit Coordinator was appointed. This change took place under the assumption that the Business Capstone Unit had been running well, with no known problems or issues in any aspect of the course, assessment or otherwise. The Unit had been undergoing constant revision and improvement for the past few years leading up to that point, so there was no reason to suspect anything untoward was occurring. However, examination of the University's online system for anonymously gathering and reporting student feedback on their learning experiences (eValuate) pointed to contract cheating problems. In the Business School's Sydney campus it was claimed that some students were engaging in contract cheating by paying a thirdparty to help them win the simulation component of the Unit, hence gaining full marks (see Table 2). This notification in eValuate in the Sydney campus was followed by similar comments in Singapore, Malaysia, and Perth campuses.

The discovery of alleged contract cheating was a novel experience for the new Unit Coordinator, and upon each anonymous report more was being learnt about the process. The University has a very thorough academic misconduct process in place, and all possible steps were being taken to comply with this process. The fact that the alleged misconduct occurred in the simulation assessment was a positive from the enforcement perspective, as this allowed significant evidence to be presented within the alleged cases which otherwise would not have been available. This significant evidence included the number of simulation logins per student, the number of times the simulation was saved, and the changes that 
Table 2 eValuate feedback from 2015 that indicated there was a contract cheating problem with the simulation in the Unit

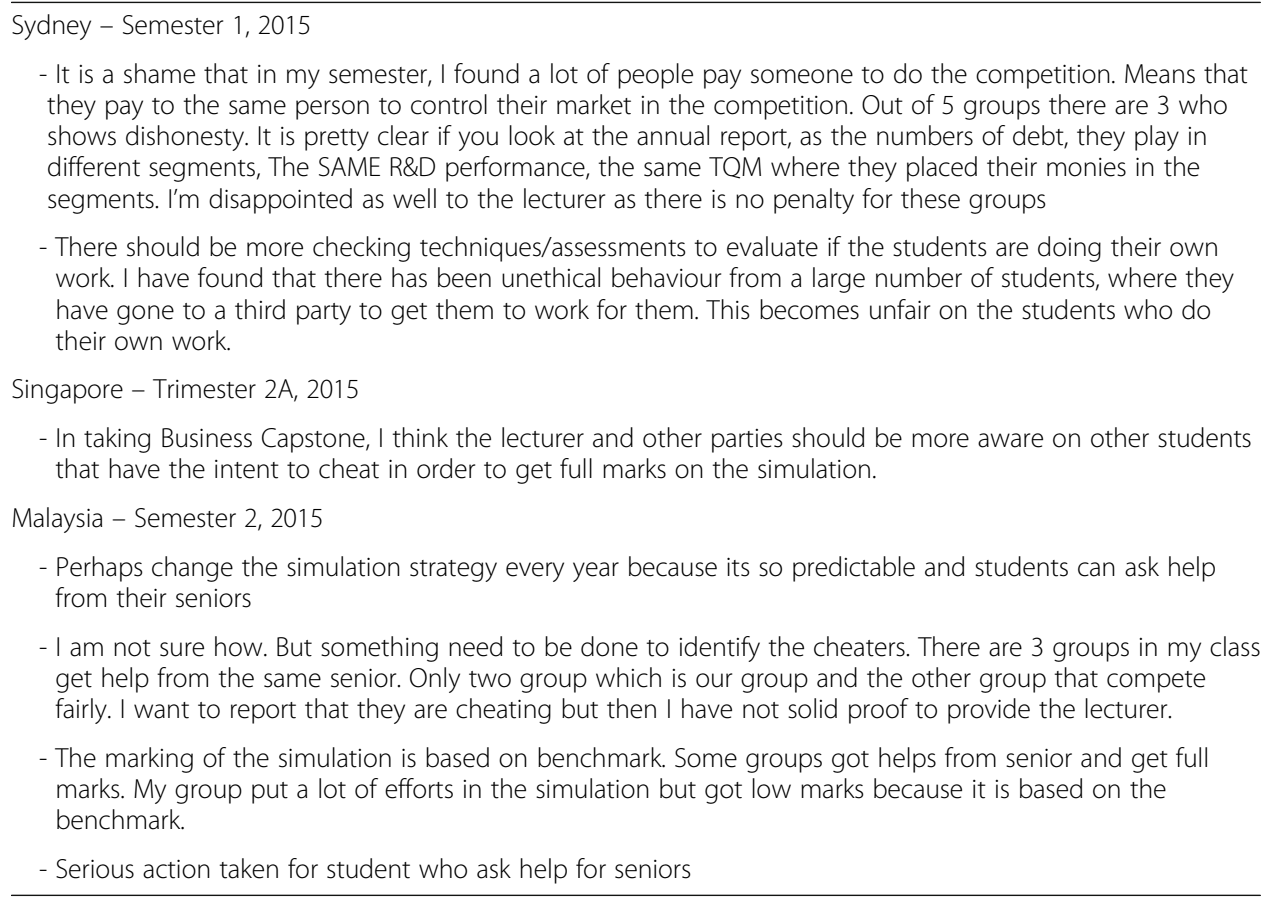

were made within the simulation system. Often these numbers were much lower than normal due to the simulation being completed by a non-student 'expert'. It also allowed for comparisons between different teams, whether in the same class or not. This capacity was important, as through this investigation it was found, as per the eValuate feedback (Table 2), that data for numerous teams, often spread across different classes, were close-to, if not precisely, identical. The odds of this outcome occurring naturally by chance alone (and with no sinister intervention) in a simulation with so many variables are astronomically small, especially when the simulation unfolds over numerous weeks across varying classes with different competitors involved. A more plausible explanation was that a common thirdparty was providing equivalent model parameters to multiple groups, ensuring their success in the simulation with minimal effort and no understanding of the process.

In response to the eValuate feedback and the concerning patterns that emerged from the initial investigation, staff members from the Unit and the Office of the Academic Registrar were sent to Sydney and Malaysia to interview students. Students accused of academic misconduct were interviewed to determine (a) their knowledge level of the simulation, (b) their understanding of contract cheating (specifically), and (c) their understanding of academic misconduct (generally). A student within a team that scored full-marks for the simulation would be expected to have a thorough understanding of the simulation, even weeks or months after its completion. The interviews revealed that in many instances this was not the case. Through the interview process, an admission to contract cheating was gained in Sydney in response to the allegations. An emailed testimony was also gained in response to the allegations from the Perth students, meaning no interview was required. Despite the lack of a declaration of guilt from students in Malaysia, the evidence was substantial enough that the allegations 
proceeded and the outcome was that student misconduct had occurred. Similarly, based on the weight of evidence alone, students in Singapore were found guilty without interview or confession. In total, through the investigations conducted in 2015, 183 alleged cases of academic misconduct were submitted and 51 annulment grades (ANN) were given for the Unit. It is highly likely that in 183 cases students participated in contract cheating, but the evidence was not conclusive enough. This was not a trivial outcome as the Business Capstone Unit was in the student's final study period meaning that these findings of academic misconduct inhibited students from graduating and potentially starting a graduate position in the workforce. In some cases, where a student had already received their degree as they chose not to attend a graduation ceremony, the degree had to be revoked!

At the completion of 2015 the Unit was in crisis. The whole summer period of 2015/ 2016 was spent working to improve the Unit and minimise, if not eliminate, the contract cheating within the simulation and more broadly in the entire Unit. The mission statement for this work was simple: continue to improve the Unit and make it harder for students to participate in and get away with contract cheating, but not any harder for students legitimately learning the material. In an effort to rectify the situation and see the mission statement come to fruition, the simulation providers in the USA were consulted at length along with appropriate stakeholders in the Business faculty.

\section{The interventions}

The investigations into contract cheating made it clear that this had been occurring for a number of years within the Unit. In response to discovering this problem the new Unit Coordinator was determined to intervene. The alterations and improvements outlined in this section were developed and implemented with no awareness of the rational choice perspective and the situational crime prevention techniques discussed above (Table 1). However, a synergy was discovered after the fact through an incidental meeting of the authors at a contract cheating forum (held in late-2016). The changes that were made are presented here with respect to this situational prevention platform, to demonstrate the applicability of this highly effective crime prevention framework to creating context-specific solutions to academic misconduct problems. Each of the improvements is discussed in turn, with attention paid to how they are consistent with the 25 techniques of situational crime prevention (summarised in Table 3). It is important to note how some of the interventions can act as a mechanism to activate multiple situational crime prevention techniques (see Sun et al., 2012, for an example of this in a different context).

\section{Anonymous feedback facility}

While the eValuate feedback was crucial evidence to begin the contract cheating investigations, its timing was very unfortunate; the anonymous eValuate feedback is released to Unit Coordinators on the same day final grades are released to students. Therefore something had to be done to try to receive this information sooner. The result was an online Google Form being created that asked for two things: (a) Student Feedback, noting that all feedback is submitted anonymously, and (b) Industry ID; every Business Capstone class in every location has a unique Industry ID which denotes the student's location and tutor. The link to this Google Form was embedded within the simulation 
to emphasise to students that it was anonymous (students may perceive that the feedback is traceable if embedded in the LMS). With students being aware of this anonymous feedback facility (it is heavily publicised in the Unit), and looking at the situational crime prevention 25 techniques, this intervention works to increase the risk for students considering contract cheating (by extending guardianship and assisting natural surveillance) and reduce provocations for engaging in this behaviour (by neutralising peer pressure).

\section{A board shake-up}

A board shake-up was introduced into the simulation. In order to mirror the reality of the workplace, at the completion of competition round 4 (the mid-point of the competition), a member of each team is chosen at random to switch companies. Teams are required to integrate their new member into the team and protect their strategy from their exiting member. This has big implications for a student team who is paying a third party to complete the work for them, so with respect to contract cheating and situational prevention, this intervention simultaneously increases effort (thus deflecting offenders), increases the risk (thereby assisting natural surveillance of behaviour from student peers), and reduces provocations (by neutralising peer pressure within groups). Conversely, there are also positives associated with this intervention for the students who are doing the work themselves, because it teaches important teamwork and adaptability lessons that have relevance to the workplace.

\section{Red flag system}

The simulation provider developed a red flag system that sends a notification via email when a student team has expert-looking performance, according to certain performance criteria. Students are made aware of the presence of this system in class, but the details of the performance criteria rules are not publicised, meaning that students are aware of the potential for detection in this manner but uncertain of the scope of this oversight. This is not conclusive evidence that misconduct is occurring, but rather an early warning system for a conversation to take place; if the red flag system has been set off and the student team cannot answer basic questions about their team's performance, there is a discrepancy and hence a problem. From a situational prevention perspective, this intervention works to increase the effort (thus deflecting offenders), increase the risk (by strengthening formal surveillance of performance), and reduce the provocations for contract cheating (by reducing temptation and arousal).

\section{Increased variability between classes}

Increased variability between individual classes was implemented. This meant that every class running for the Unit had different market conditions, whereas previously this was only different per campus location. This increased variation acts to reduce the rewards of contract cheating (by disrupting the 'expertise' in the markets) and further reduces provocations (by reducing temptation and arousal) as this decreases the chances of students possessing meaningful, relevant information for sharing the data between classes. 
Increased the skill of the computer competitor

In a standard classroom for the Unit there are 25 students. This is by design, as it allows five teams of five students per class. These teams are moderated within the simulation by a computer competitor, as good human teams will be able to beat the computer competitor, whereas poor teams will be beaten by the computer competitor. Prior to the restructure of the Unit, the computer competitor was set to an 'average' level difficulty. Following the intervention, the skill level of the computer competitor was increased to provide a 'strong' level difficulty against which human teams were required to compete. As a result of this change, the 'strong' computer competitor is still beatable, but this happens much less frequently than with the 'average' computer competitor, previously. This intervention allows further checks within the simulation, as human teams who are convincingly beating the 'strong' computer competitor, especially at an early stage, warrant questioning to ensure they know what they are doing. In terms of the recognised situational prevention techniques, this intervention increases the chances of detecting contract cheating by strengthening formal surveillance of high performance.

\section{Students have optional extra simulation practice}

As a result of the intervention, students participating in the Unit now have the option to complete the Simulation Footrace for extra practice. The Simulation Footrace is a stand-alone simulation competition that is free for all registered students to participate in. This is an optional tool for students to complete in their own time outside of class. The Simulation Footrace can be run by teams or by individuals. All participant teams compete against a common set of computer competitors. Participants can proceed at their own rate, completing between 1 to 8 simulation rounds in their own time. This facility allows students to undertake extra simulation practice, thus providing them with appropriate experience, and positioning them well to ask meaningful questions of their tutor before the assessed simulation begins. It also allows students to get more familiar and comfortable with the simulation outside of class which reduces the need for contract cheating. In terms of situational prevention, this intervention simultaneously reduces the provocations for contract cheating (by reducing frustrations and stress for struggling students) and removes the excuses for cheating (by assisting compliance with the assessment expectations).

\section{Introducing a timing mechanism for the preparation task}

The preparation task component of the business simulation is due in Week 3 (25\% of the way through the Unit) and should take students between one and three hours to complete. Once the contract cheating problem with the Unit had been identified, analysis of this assessment item demonstrated that some students were completing this task in an astonishingly short time (3-5 min), which implied misconduct was occurring. As a result of the changes to the Unit, a timing mechanism was introduced to this assessment within the simulation. This timing mechanism allows the tutor to check the length of time taken to complete the tasks; if the time is unusually quick, the tutor can then talk to the student to determine what is happening (with potential reasons including a very good student, contract cheating, or technology issue). This timing oversight also shows students they are being monitored in many elements of their assessments, which is beneficial at such an 
early stage of the Unit, and solely works to increase risk, and hence decrease the chances of engaging in contract cheating (by extending guardianship, using place managers, and strengthening formal surveillance).

\section{Academic misconduct information distributed to students}

Through formal student interviews and informal student discussions it was found that while most students are aware of what academic integrity is, very few are aware of what exactly constitutes student misconduct or the range of penalties that can be given. This information is available for students in the assessment policy manual, but is often overlooked, or not even found in the first place. Due to this, a custom-made 2-page academic misconduct handout is now printed and distributed to all students in all locations in Week 2 of the study period. This outlines exactly what misconduct is and provides details about the penalties that can be given for this behaviour. The term contract cheating is not mentioned specifically in this document, as it was feared many students would not understand its meaning. Rather, examples of behaviours that constitute misconduct have been added to the document, some of which are clearly contract cheating. This is an easily digestible piece of information and this intervention prevents students from claiming ignorance about academic integrity matters. In situational prevention terms this intervention reduces provocations for contract cheating (reducing temptation and arousal) and removes the excuses for this choice (by setting rules, posting instructions, and alerting a student's conscience).

\section{Utilising academic misconduct procedures against contract cheaters}

The University has a set process for reporting and recording academic misconduct, yet it is not used as often as it should due to additional paperwork requirements and length of time to receive an outcome. Therefore, in addition to the academic misconduct information handout explained above, official university posters were also posted in the Units' classrooms showing the academic misconduct procedures. Tutors were also advised to explain past cases of contract cheating and the outcomes of these cases for the students involved. This intervention contributed to the prevention of contract cheating by reducing the rewards for this behaviour (demonstrating the denial of benefits when caught) and reducing the provocations for cheating (by discouraging imitation).

\section{Reformatting the requirements for the company presentation}

A re-format of the company presentation occurred. Instead of students presenting the running of their own company in the simulation to the class, students now act as a corporate advisory division of an independent consulting organisation and present on a company that is not their own. Students are given one week from the completion of the simulation to their presentation, and in this time must analyse eight rounds of another company's business decisions. The purpose of this is to ensure students have a thorough understanding of the business simulation more broadly. In terms of situational prevention, this initiative minimises contract cheating by increasing the effort (deflecting offenders), reducing the rewards (denying the benefits of cheating), and reducing provocations (by reducing temptation and arousal). As with the board shake-up intervention discussed above, this assessment variation also resulted in positive learning experiences for students who were actively participating in the Unit because it acts to prepare students 
for challenges working in consultancies, which research shows is where a large number of graduates will start their careers (Guthrie, 2016).

\section{Invigilation of eTests}

As a result of the redesign, the weekly eTests that were formerly done outside of the class are now done in-class as invigilated pieces of assessment. This was designed to reduce the frequency of all types of cheating by increasing the effort involved (thus deflecting offenders) and increasing the risk (through the use of place managers and by strengthening formal surveillance).

\section{Removal requests from websites}

A quick internet search on the Unit found many assignment sharing websites with material owned by the Unit available for download. Students post material to these websites as they receive credit to download other students' materials, or in some cases receive money. While not all the material found was property of the Unit (such as student assignments), much of it was, including unit outlines, lecture notes and eTest questions. In cooperation with the University's legal department an official takedown notice was sent to the websites. The offending material was removed as per the websites abiding by the Digital Millennium Copyright Act (DMCA). For students looking to engage in unethical behaviour relating to the assessment items for this Unit, these steps simultaneously increased the effort (by target hardening) and reduced the rewards (by removing suitable targets and disrupting available markets).

\section{Enhanced tutor education with respect to academic misconduct}

All tutors in all locations were made aware of the cases of misconduct (detection, investigation, and outcome) and were informed of the design improvements that had been implemented in the Unit. The tutors were also instructed to report anything unusual to the Unit Coordinator at any time, regardless of how trivial it may appear. It is important to support the tutors as they are the front line to the students and often the only human contact with the Unit. They have a wealth of experience that can be utilised to implement elements of a situational prevention approach to dealing with academic misconduct by increasing the effort required (by target hardening) and increasing the risk involved (due to the presence of capable place managers and strengthened formal surveillance practices).

\section{Introduced updated, bespoke case study videos}

With a view to resetting the context for the assessment in the Unit, the individual case study videos from 2015 were also discarded. Over the course of 2015, a total of 18 new custom video cases were recorded from managing directors and CEOs. These bespoke videos form the basis of the individual case study report assessment, with a case taken from real people in real companies, including Fortune 500 companies, NGOs, state utilities and Indigenous organisations in Perth, Singapore, and Malaysia. As these cases are custom-made for the Unit, and only one is used per semester/trimester, they can be used once and then retired, reducing the chances of further misconduct. With respect to reducing the opportunity for contract cheating, this restricted, scheduled use of 


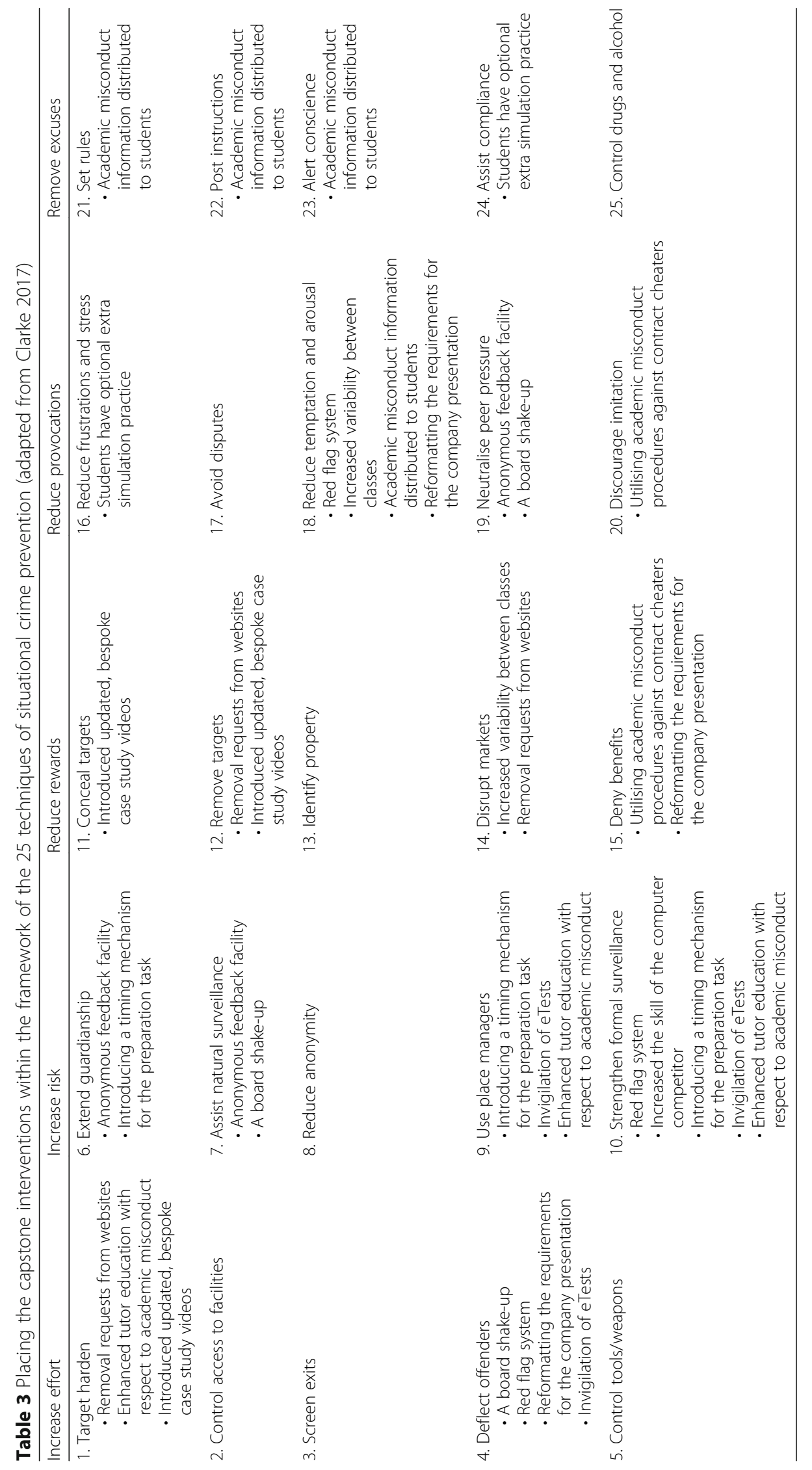


videos increases the effort involved (by target hardening) and reduces the rewards for cheating (by concealing and removing suitable targets).

\section{The impact of the interventions}

At the time of publication, one year after implementing these changes, the number of alleged cases of academic misconduct across all assessments in the Unit had reduced to 27, down from 183 alleged cases in 2015. Not only this, but in semester 1, 2016, students in Perth reported directly to the Unit Coordinator that misconduct was occurring within their group. They explained that one group member had a 'friend' in Singapore who claimed to be a world expert at the simulation. Every member of this five person group had then been added to a private social media group that included this individual. The non-student 'expert' then proceeded to give very specific advice relevant only to their company in the simulation. The two whistle-blowers who reported this provided the Unit Coordinator with screenshots from group chats as evidence of this situation. The combination of factors that had been manipulated for the 2016 iteration of the Unit meant that the suitability of this opportunity for contract cheating had been altered such that the perceived risks and effort involved with this misconduct were now outweighing the potential rewards of this choice. The excuses for this behaviour had been removed. The whistleblowers knew that engaging in contract cheating was wrong and they were worried about being caught. As a result of this testimony, the whistle-blowers did not face an academic misconduct investigation. The other members of the group were not as fortunate.

It is important to emphasise that while these changes do appear to have successfully reduced the occurrences of academic misconduct in the Unit, they have not hindered any genuine students' ability to complete the Unit and score a high grade, and as such, are consistent with the aim of implementing teaching and supporting learning that influence, motivate, and inspire students to learn. Furthermore, the changes have also allowed the Unit to become more integrated and have given students further opportunities to develop themselves in anticipation for entering the workplace. Overall, these changes have ensured the high quality standards set by the University are upheld, and students graduate having a strong understanding of misconduct processes, what it entails, and penalties if caught.

\section{Conclusions}

As Clarke (2017) explains, the key to effectively implementing situational crime prevention is for practitioners to be very specific about what it is they are trying to prevent. This problem specificity lends itself well to understanding how the crime is currently being committed. Knowledge about 'how' then triggers an action research process in which the problem specificity leads to targeted interventions designed to reduce the problem. The outcome of this intervention process is monitored to ensure it was implemented properly and to see if it had an impact on the problem. Practitioners aiming to prevent problems in this way are encouraged to consider all potentially viable solutions at the response phase and to implement a range of interventions in parallel. Ongoing monitoring is then required to ensure the problem does not return. These elements have been implemented with respect to the Business Capstone unit and, as can be seen from Table 3; the risk, reward, effort, excuses, and provocations for contract cheating in this context have been fundamentally adjusted. The end result is a reduction in this problem 
with no expectation that it will return in its original form. The case study presented highlights the importance of assessment design to reduce contract cheating, as often academics cannot control the penalties given for contract cheating, but can modify the assessments to prevent it in the first place. The logic of this approach can be generalised to other academic integrity issues (see Hodgkinson et al., 2015), potentially arming other academics to adjust the assessment opportunity structures within their units to reduce the suitability for contract cheating. Utilising this framework for problem prevention draws on creativity and innovation in assessment design and delivery, building on the belief that prevention is better than a cure, and usually less expensive.

\section{Endnotes}

${ }^{1}$ See www.popcenter.org/ for almost 250 successful case studies where this framework has been used by police and governments to prevent crime and safety problems.

${ }^{2}$ Interested parties should read the work by Farrell, Tilley, and Tseloni (2014) that examines the role situational crime prevention and opportunity reduction has played in the global crime drop that has occurred since the early 1990s (which is best explained by the 'security hypothesis' and the general reduction in opportunity for burglary and vehicle theft).

Acknowledgements

No acknowledgements outside the authors are required.

Authors' contributions

Both authors contributed equally to this manuscript.

Competing interests

Neither of the authors have any competing interests in the manuscript.

\section{Publisher's Note}

Springer Nature remains neutral with regard to jurisdictional claims in published maps and institutional affiliations.

\section{Author details}

${ }^{1}$ Curtin Business School, Curtin University, Rm 408.2008, Kent Street, Bentley, WA 6102, Australia. ${ }^{2}$ Murdoch University,

90 South Street, Murdoch, WA 6150, Australia.

Received: 19 May 2017 Accepted: 20 August 2017

Published online: 14 September 2017

\section{References}

Clarke, R., \& Lancaster, T. (2006). Eliminating the successor to plagiarism? Identifying the usage of contract cheating sites Proceedings of 2nd International Plagiarism Conference

Clarke RV (2017) Situational crime prevention. In: Wortley R, Townsley M (eds) Environmental criminology and crime analysis, 2nd edn. Willan Publishing, Cullompton, UK, pp 286-303

Cornish DB, Clarke RV (1986) The reasoning criminal: rational choice perspectives on offending. Springer-Verlag, NY

Cornish DB, Clarke RV (2017) The rational choice perspective. In: Wortley R, Townsley M (eds) Environmental criminology and crime analysis, 2nd edn. Willan Publishing, Cullompton, UK, pp 29-61

Curtis GJ, Clare J (2017) How prevalent is contract cheating and to what extent are students repeat offenders. Journal of Academic Ethics 15(2):115-124. DOl:10.1007/s10805-017-9278-x

Curtis GJ, Vardanega L (2016) Is plagiarism changing over time? A 10-year time-lag study with three points of measurement. High Educ Res Dev. doi:10.1080/07294360.2016.1161602

Eck JE (2015) Who should prevent crime at places? The advantages of regulating place managers and challenges to police services. Policing 9(3):223-233. doi:10.1093/police/pav020

Farrell G, Tilley N, Tseloni A (2014) Why the crime drop? Crime and justice 43(1):421-490

Guthrie, B. (2016). Graduate destinations 2015: a report on the work and study outcomes of recent higher education graduates. Melbourne, VIC http://www.graduatecareers.com.au/wp-content/uploads/2016/07/GraduateDestinations-Report-2015-FINAL1.pdf

Hodgkinson T, Curtis H, MacAlister D, Farrell G (2015) Student academic dishonesty: the potential for situational prevention. Journal of Criminal Justice Education. doi:10.1080/10511253.2015.1064982

Lancaster, T., \& Clarke, R. (2017). Rethinking assessment by examination in the age of contract cheating Plagiarism Across Europe and Beyond 2017, (pp. 215-228). Brno, Czech Republic 
Leclerc B (2017) Crime scripts. In: Wortley R, Townsley M (eds) Environmental criminology and crime analysis, 2nd edn. Willan Publishing, Cullompton, UK, pp 119-141

Maxwell A, Curtis GJ, Vardanega L (2006) Plagiarism among local and Asian students in Australia. Guidance and Conselling 21:210-215

Ogilvie J, Stewart A (2010) The integration of rational choice and self-efficacy theories: a situational analysis of student misconduct. The Australian and New Zealand Journal of Criminology 43(1):130-155

Rigby D, Burton M, Balcombe K, Bateman I, Mulatu A (2015) Contract cheating and the market in essays. J Econ Behav Organ 111:23-37

Sun J, Prenzler T, Buys N, McMeniman M (2012) Preventing smoking in open public places in university campus settings: a situational crime prevention approach. Health Educ 112(1):47-60. doi:10.1108/09654281211190254

Walker M, Townley C (2012) Contract cheating: a new challenge for academic honesty. Journal of Academic Ethics 10(1):27-44

Wallice MJ, Newton PM (2014) Turnaround time and market capacity in contract cheating. Eduational Studies 40(2): 233-236. doi:10.1080/03055698.2014.889597

Zafarghandi AM, Khoshroo F, Barkat B (2012) An investigation of Iranian EFL masters students' perceptions of plagiarism. Int J Educ Integr 8:69-85

Submit your manuscript to a SpringerOpen ${ }^{\circ}$ journal and benefit from:

- Convenient online submission

- Rigorous peer review

- Open access: articles freely available online

- High visibility within the field

- Retaining the copyright to your article

Submit your next manuscript at $\gg$ springeropen.com 